\title{
Low Molecular Weight Heparins as Extended Prophylaxis Against Recurrent Thrombosis in Cancer Patients
}

\author{
Cocav A. Engman, MD, and Leo R. Zacharski, MD, Lebanon, New Hampshire
}

\section{Key Words}

Cancer, venous thromboembolism, thromboprophylaxis, low molecular weight heparins

\begin{abstract}
Cancer has been shown to be an independent risk factor for the development of venous thromboembolism (VTE; deep vein thrombosis and pulmonary embolism). Thromboprophylaxis reduces the incidence of VTE in patients with cancer; however, active cancer places patients at high risk for recurrent VTE, necessitating extended prophylactic regimens. Extended prophylaxis in patients with cancer can be problematic because of increased risk for bleeding. Oral anticoagulants, such as warfarin, have been the standard of care for extended prophylaxis, but maintaining a clinically effective level of anticoagulation can be difficult because of a wide range of drug interactions, a narrow therapeutic window, and an increased risk of bleeding complications, particularly in patients with cancer. Recent evidence indicates that long-term prophylaxis with low-molecularweight heparins (LMWHs) is an effective and safe alternative to oral anticoagulation in patients with VTE and cancer, reducing the risk for recurrent VTE by up to $52 \%$. LMWHs can also be seen as cost-effective for long-term prophylaxis, because higher drug acquisition costs are offset by the potential for reduced hospital stays, reduced need for coagulation monitoring, and fewer bleeding complications. Some studies suggest that LMWHs may also have direct antitumor effects and improve survival rates, most notably in patients with non-metastatic disease. Further clinical research is needed to evaluate the potential survival benefits of LMWH therapy in patients with cancer. (JNCCN 2008;6:637-645)
\end{abstract}

From the Section of Hematology/Oncology, Norris Cotton Cancer Center, Dartmouth Hitchcock Medical Center, Lebanon, New Hampshire.

Submitted June 14, 2007; accepted for publication January 20, 2008. Dr. Zacharski has been a consultant for AstraZeneca, Bayer, Pfizer, and sanofi-aventis. The authors received editorial support in the preparation of this manuscript, funded by sanofi-aventis, U.S. The authors affirm that they are fully responsible for the content and editorial decisions regarding this manuscript.

Correspondence: Leo Zacharski, MD, VA Medical and Regional Office Center, 215 North Main Street, White River Junction, VT 05009. E-mail: Leo.R.Zacharski@dartmouth.edu
The association between thrombosis and cancer is a double-edged sword: patients with cancer are at increased risk for venous thromboembolism (VTE), and standard therapy for VTE puts cancer patients at increased risk for bleeding. The risk for VTE in patients with cancer is 6 times higher than in people without cancer, ${ }^{1}$ and thrombosis is the second most common cause of death in patients with cancer. ${ }^{2}$ One analysis that used Kaplan-Meier survival curves to evaluate patient discharge information, recorded through Medicare, after 6 months showed that patients with both cancer (all malignancies analyzed together) and VTE have a $94 \%$ probability of dying. This is more than twice the mortality rate for patients with malignant disease without VTE (42\%) and 3 times the rate of patients with deep vein thrombosis (DVT) or pulmonary embolism (PE) without known concurrent malignancy (29\%) during the same period. ${ }^{3}$

In a recent analysis of mortality rates in cancer patients with VTE receiving chemotherapy as outpatients, the annualized death rate was 47 -fold higher $(95 \% \mathrm{CI}$, $6-89 ; P=.03)$ compared with the general population. ${ }^{4}$ Approximately 1 of 7 deaths in hospitalized cancer patients are reportedly due to fatal $\mathrm{PE}$, rather than their malignancy, and $60 \%$ of these patients had localized cancer or limited metastases that would have allowed for a better prognosis in the absence of fatal PE. ${ }^{5}$

This strong association between cancer and the development of VTE may be attributed to inherent disturbances in the hemostatic mechanisms that cause hypercoagulability during active malignancy. Other thrombotic risk factors that commonly affect patients with cancer include frequent surgical procedures, periods of immobility, placement of indwelling central venous catheters, and use of chemotherapy, hormone therapy, and radiotherapy (Figure 1).1,6 
Engman and Zacharski

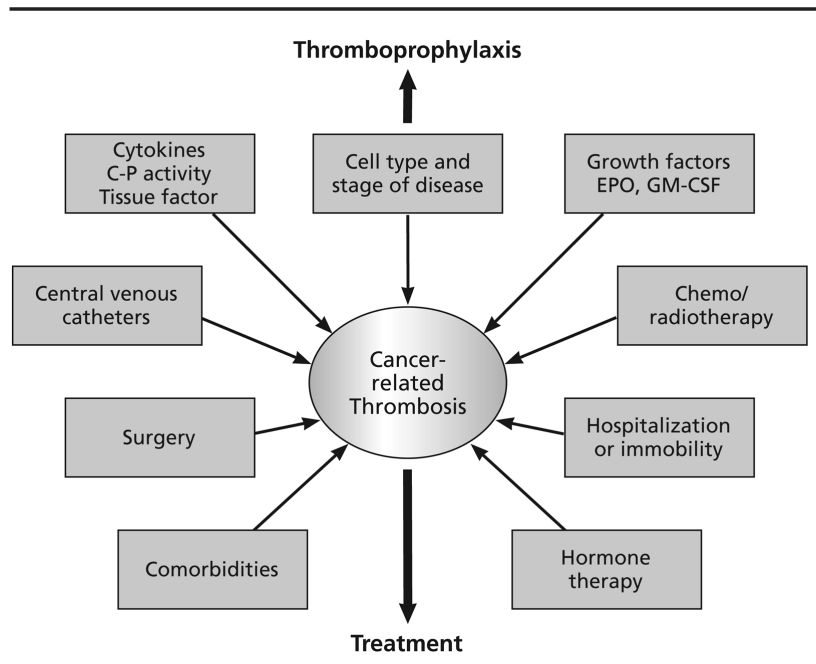

Figure 1 Common risk factors for cancer-related thrombosis. Abbreviations: C-P, cysteine proteases; EPO, erythropoietin; GM-CSF, granulocyte-macrophage colony-stimulating factor.

This review discusses extended VTE prophylaxis in cancer patients and compares vitamin $\mathrm{K}$ antagonist (VKA) therapy currently used for extended outpatient prophylaxis with low molecular weight heparins (LMWHs), which may be used for both long-term prevention and secondary prophylaxis in cancer patients. Importantly, although one study reported VTE complications in patients specifically with leukemia, ${ }^{7}$ most studies discussed included mixed populations of patients with solid and hematologic cancer subtypes. Consequently, this review focuses mainly on the findings in solid tumors; the predominant type of cancer in each study has been mentioned for reference.

\section{Background}

Antithrombotic therapy, both treatment and prophylaxis, has been shown to reduce morbidity and mortality caused by VTE in patients with cancer. ${ }^{8,9}$ However, treating these patients with anticoagulants is challenging because of the increased risk for bleeding $^{10-13}$ and recurrent VTE. ${ }^{11-16}$

Prophylaxis with either LMWH or low-dose unfractionated heparin (UFH) is effective in cancer patients undergoing surgery or hospitalized for acute illness. For surgical cancer patients, the regimen should be adapted according to the type of surgery, and in cancer patients bedridden for medical illness, prophylaxis regimens should be administered as in other high-risk patients. ${ }^{8}$ Additionally, a population-based cohort study by Heit et al., ${ }^{16}$ reported that the risk for recurrent

VTE is 2-fold higher in patients with cancer than in those without malignancy and that the risk of recurrence is further increased in patients with cancer receiving chemotherapy (4-fold increase in relative risk of recurrent VTE). Therefore, the treatment of VTE in cancer patients must be in proportion with the inherent risk of recurrence.

Oral VKAs, particularly warfarin, have been the mainstay of therapy for secondary prophylaxis. However, VKAs have a narrow therapeutic index and are subject to a wide range of drug and food interactions. Maintaining therapeutic anticoagulation may be problematic, requiring regular monitoring and dose adjustment. This is particularly important in cancer patients because maintaining a therapeutic international normalized ratio (INR) in this population is difficult and these patients are at increased risk for adverse events. ${ }^{6}$ Consequently, interest has grown in using LMWHs as an alternative for long-term therapy.

\section{Limitations of VKA Anticoagulation in Cancer}

\section{Slow Onset of Action}

Warfarin therapy typically requires 3 to 5 days to reach therapeutic anticoagulation levels, ${ }^{17}$ because the therapeutic effect depends on the levels of circulating vitamin $\mathrm{K}$ factors and because the pharmacokinetic profile is influenced by various genetic and environmental factors. Consequently, the guidelines of the American College of Chest Physicians (ACCP) strongly recommend (grade $\mathrm{A}$, defined as a strong recommendation based on data from randomized clinical trials) "bridging" anticoagulation with either LMWH or UFH until therapeutic anticoagulation (determined by an INR) is achieved., ${ }^{9,17}$

Vitamin K1 (phylloquinone) can be used to reverse or interrupt anticoagulation in cancer patients who need emergency surgical procedures or who have chemotherapy-induced thrombocytopenia or bleeding. Alternatively, administration of recombinant clotting factors or transfusion with fresh-frozen plasma can also be considered in these patients. LMWHs have a stable pharmacokinetic profile, ${ }^{18}$ and patients on LMWH prophylaxis often do not need anticoagulation reversed.

\section{Maintenance of Therapeutic Anticoagulation}

Patients receiving long-term oral anticoagulation require frequent monitoring of the prothrombin time 
Low Molecular Weight Heparins in Cancer

to ensure that the INR remains within the target therapeutic range. Daily monitoring is needed at the beginning of treatment, but monitoring can usually be reduced to every 1 to 4 weeks after a stable dose response is achieved. However, anticoagulation levels reached using VKA are affected by factors such as vomiting, diarrhea, malnutrition, impaired gastrointestinal uptake, and liver dysfunction. Thus, anticoagulation status may need to be re-evaluated multiple times.

In addition, the anticoagulant effect of VKAs can be affected by a wide range of drug and food interactions (Table 1). ${ }^{17}$ Thus, the INR must be reconsidered whenever a new drug is added or removed from the patient's treatment regimen. For example, a high incidence of INR abnormalities has been reported in patients receiving fluorouracil (FU)-based chemotherapy concomitantly with minidose warfarin prophylaxis for catheter-associated thrombosis. ${ }^{19}$ Some evidence also suggests that tamoxifen may potentiate the anticoagulant effect of warfarin. ${ }^{17}$ Equally, agents such as aspirin and non-steroidal anti-inflammatory drugs (NSAIDs) may increase the risk of anticoagulant-related bleeding caused by inhibition of platelet function, their potential to cause gastric lesions, ${ }^{17}$ and competitive binding of NSAIDs and warfarin to albumin.

Because of drug interactions and the metabolic side-effects of cancer therapy, cancer patients often have non-therapeutic INR values for a greater proportion of time than patients without cancer. ${ }^{20-22}$ In one study that investigated the use of warfarin for the primary prevention of VTE in ambulatory patients with metastatic breast cancer, the INR was below the predefined target of 2.0 to 3.0 on $30 \%$ of days, on target for $46 \%$, and above target for $24 \%$ of the time. ${ }^{21}$ If an INR is subtherapeutic, the patient may be insufficiently protected against VTE; ${ }^{11}$ conversely, a supratherapeutic INR puts the patient at risk for bleeding complications. ${ }^{23}$ Because of the complexity of maintaining therapeutic levels of warfarin long-term, alternative approaches are being pursued. ${ }^{21,24,25}$

\section{LMWH Therapy in Cancer Patients Efficacy and Safety}

A number of randomized clinical trials compared the efficacy and safety of LMWH with oral anticoagulant therapy for the prevention of recurrent VTE in patients with cancer. The Randomized Comparison of

\begin{tabular}{|c|c|}
\hline Increases Anticoagulant Effect & $\begin{array}{l}\text { Inhibits Anticoagulant } \\
\text { Effect }\end{array}$ \\
\hline Anabolic steroids & Antibacterials: \\
\hline \multirow{2}{*}{$\begin{array}{l}\text { Analgesics: } \\
\text { Dextropropoxyphene, } \\
\text { propoxyphene }\end{array}$} & Nafcillin, rifampin \\
\hline & $\begin{array}{l}\text { Anticonvulsant: } \\
\text { Carbamazepine }\end{array}$ \\
\hline \multirow{2}{*}{$\begin{array}{l}\text { Antiarrhythmics: } \\
\text { Amiodarone, disopyramide, mori- } \\
\text { cizine, propafenone, quinidine }\end{array}$} & $\begin{array}{l}\text { Antidepressant: } \\
\text { Trazodone }\end{array}$ \\
\hline & Anti-fungal: \\
\hline \multirow{3}{*}{$\begin{array}{l}\text { Antibacterials: } \\
\text { Cefamandole, cefazolin, } \\
\text { ciprofloxacin, cotrimoxazole, } \\
\text { erythromycin, metronidazole, } \\
\text { nalidixic acid, norfloxacin, } \\
\text { ofloxacin, sulfisoxazole, tetracyline }\end{array}$} & Griseofulvin \\
\hline & Barbiturates \\
\hline & $\begin{array}{l}\text { Food-related: } \\
\text { Enteral feeding, } \\
\text { foods with high }\end{array}$ \\
\hline \multirow{2}{*}{$\begin{array}{l}\text { Anticoagulants: } \\
\text { Acetylsalicylic acid, heparin }\end{array}$} & vitamin $\mathrm{K}$ content \\
\hline & $\begin{array}{l}\text { Hypnotic/sedative: } \\
\text { Chlordiazepoxide }\end{array}$ \\
\hline $\begin{array}{l}\text { Antiepileptic: } \\
\text { Phenytoin }\end{array}$ & $\begin{array}{l}\text { Immunosuppressants } \\
\text { Cyclosporine }\end{array}$ \\
\hline $\begin{array}{l}\text { Antiestrogen: } \\
\text { Tamoxifen }\end{array}$ & $\begin{array}{l}\text { dicloxacillin, } \\
\text { azathioprine }\end{array}$ \\
\hline $\begin{array}{l}\text { Anti-fungals: } \\
\text { Fluconazole, itraconazole, } \\
\text { miconazole }\end{array}$ & $\begin{array}{l}\text { Lipid-lowering drug: } \\
\text { Cholestyramine }\end{array}$ \\
\hline $\begin{array}{l}\text { Antihypertensive: } \\
\text { Propanolol }\end{array}$ & $\begin{array}{l}\text { Psiorasis treatment: } \\
\text { Etretinate }\end{array}$ \\
\hline $\begin{array}{l}\text { Cancer therapy: } \\
\text { Fluorouracil, ifosphamide }\end{array}$ & $\begin{array}{l}\text { Ulcer treatment: } \\
\text { Sucralfate }\end{array}$ \\
\hline \multicolumn{2}{|l|}{$\begin{array}{l}\text { Diuretic: } \\
\text { Metozalone }\end{array}$} \\
\hline \multicolumn{2}{|l|}{$\begin{array}{l}\text { Hypnotic/sedative: } \\
\text { Chloral hydrate }\end{array}$} \\
\hline \multicolumn{2}{|l|}{$\begin{array}{l}\mathrm{H}_{2} \text {-blocker: } \\
\text { Cimetidine }\end{array}$} \\
\hline \multicolumn{2}{|l|}{$\begin{array}{l}\text { Lipid-lowering drugs: } \\
\text { Clofibrate, gemfibrozil, lovastatin }\end{array}$} \\
\hline \multicolumn{2}{|l|}{$\begin{array}{l}\text { Miscellaneous: } \\
\text { Disulfam, sulfinpyrazone, alcohol } \\
\text { (with concomitant liver disease) }\end{array}$} \\
\hline \multicolumn{2}{|l|}{$\begin{array}{l}\text { NSAIDs: } \\
\text { Acetominofen, indomethacin, } \\
\text { ketoprofen, phenylbutazone, } \\
\text { piroxicam, sulindac, tolmetin, } \\
\text { topical salicylates }\end{array}$} \\
\hline \multicolumn{2}{|l|}{$\begin{array}{l}\text { Proton pump inhibitor: } \\
\text { Omeprazole }\end{array}$} \\
\hline $\begin{array}{l}\text { Vaccines: } \\
\text { Flu vaccine }\end{array}$ & \\
\hline
\end{tabular}

Abbreviation: NSAIDs, non-steroidal anti-inflammatory drugs. Adapted from Ansell J, Hirsh J, Hylek E, et al. Pharmacology and management of the vitamin $\mathrm{K}$ antagonists: American College of Chest Physicians evidence-based clinical practice guidelines, 8th edition. Chest 2008:133;160S-198S. 
Low-Molecular-Weight Heparin versus Oral Anticoagulant Therapy for the Prevention of Recurrent Venous Thromboembolism in Patients with Cancer (CLOT) trial, a multicenter, randomized 6-month study, compared the efficacy of the LMWH dalteparin with an oral VKA for the prevention of recurrent VTE in patients predominantly with solid tumors. ${ }^{21}$ Patients in the LMWH group had a lower incidence of recurrent VTE (9\%; 27 of 336 patients) compared with the VKA group (17\%; 53 of 336 patients; $P=.002)$. This difference represents a $52 \%$ relative risk reduction in the LMWH group (Figure 2). Mortality rates at 6 months were 39\% in the dalteparin group and $40 \%$ in the VKA group $(P=.53)$. Rates of major bleeding complications were similar in both treatment groups, $6 \%$ in the dalteparin group and $4 \%$ in the group receiving VKA $(P=.27) .{ }^{21}$

In a multicenter, randomized clinical trial, longterm (3 months) LMWH (tinzaparin) was compared with long-term VKA (warfarin). ${ }^{26}$ An analysis of results from a subgroup of 200 cancer patients with acute symptomatic proximal-vein thrombosis showed a significant reduction in the frequency of recurrent VTE at 3 months with tinzaparin compared with warfarin (6\% vs. $10 \%)$. This effect was maintained at 12 months, with a $7 \%$ rate of recurrent VTE in the tinzaparin group compared with $16 \%$ in the warfarin group $(P=.044)$. Mortality, which was the same in the 2 groups (47\%), was predominantly determined by

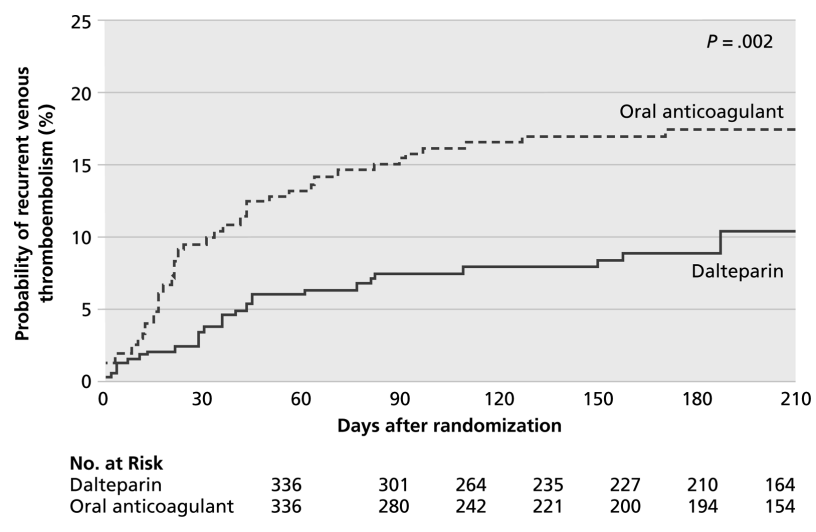

Figure 2 Relative risk of recurrent thrombotic events for a low molecular weight heparin (dalteparin) compared with a vitamin $\mathrm{K}$ antagonist as secondary thromboprophylaxis in patients with cancer (Kaplan-Meier estimates). ${ }^{19}$

Reprinted from Lee AY, Levine MN, Baker RI, et al. Low-molecularweight heparin versus a coumarin for the prevention of recurrent venous thromboembolism in patients with cancer. $\mathrm{N}$ Engl J Med 2003;349:146-153. Copyright (C) 2007 Massachusetts Medical Society. All rights reserved. cancer progression. Bleeding occurred in $27 \%$ of patients treated with LMWH tinzaparin and $24 \%$ of those treated with warfarin (absolute difference, $-3 \%$; 95\% CI, -9.1-15.1). ${ }^{26}$

The randomized, comparative, open-label Oncology and Enoxaparin (ONCENOX) trial of 102 patients with active malignancy and acute symptomatic DVT or PE showed that administration of a LMWH (enoxaparin, either $1.0 \mathrm{mg} / \mathrm{kg}$ or $1.5 \mathrm{mg} / \mathrm{kg}$ subcutaneous daily) for 180 days was as well tolerated and effective as LMWH given for 5 days followed by oral warfarin in the secondary prevention of VTE in patients with cancer. ${ }^{27}$

The comparative safety and efficacies of LMWH and warfarin as long-term secondary VTE prophylaxis were evaluated in a meta-analysis of 7 randomized studies, including 1379 patients. ${ }^{28}$ These studies involve general patient populations, but a high proportion $(66 \%)$ were patients with cancer. LMWH was associated with a statistically insignificant reduction in the risk of recurrent VTE and the risk of major bleeding, with no difference in all-cause mortality (odds ratios were 0.66 [95\% CI, 0.41-1.07]; 0.45 [95\% CI, 0.18-1.11]; and 1.19 [95\% CI, 0.78-1.83]); respectively. The authors concluded that treatment with LMWH for 3 months was as effective and well tolerated as the same period of treatment with an oral anticoagulant. ${ }^{28}$

A randomized trial involving 146 patients with mainly breast, urologic, or digestive tract cancer and with proximal DVT, compared 3 months of therapy with either warfarin or the LMWH enoxaparin for secondary prophylaxis of VTE. Warfarin treatment was associated with a $21.1 \%$ rate of recurrent VTE or major bleeding compared with a $10.5 \%$ rate in patients receiving LMWH enoxaparin, but this difference was not statistically significant $(P=.09) .{ }^{24}$ Overall, the incidence of major hemorrhage was $16 \%$ in the warfarin group compared with $7 \%$ in the enoxaparin group $(P=.09) .{ }^{24}$

A meta-analysis of 11 studies evaluated whether the incidence of recurrent VTE differed between patients treated with LMWH and those treated with oral anticoagulants. In the 4 studies that involved cancer patients, the rates of recurrent VTE were $6.5 \%$ for LMWH and $12.6 \%$ for oral anticoagulants, corresponding to a significantly lower risk of recurrent VTE with LMWH (relative risk, 0.52; 95\% CI, 0.35-0.76; 
Low Molecular Weight Heparins in Cancer

$P=.001) .{ }^{29}$ Safety findings were not included in this analysis.

Other studies have also suggested that LMWH is more effective than adjusted-dose oral VKA in reducing the incidence of recurrent VTE in cancer patients without increasing the risk of major bleeding events. ${ }^{6,30,31}$

\section{After Recurrent VTE During Warfarin Therapy}

LWMH has been found to be effective as extended prophylaxis in patients with cancer who have experienced recurrent VTE while on warfarin therapy. ${ }^{32-34}$ One study suggests that long-term prophylaxis with LMWH may be of particular benefit in preventing recurrent VTE in high-risk patients with advanced or metastatic cancer who have suffered extensive primary thrombosis. ${ }^{31}$

\section{Possible Survival Advantage and Antitumor Effects} In addition to the benefits of extended LMWH therapy in reducing VTE recurrence, increasing evidence suggests that LMWH therapy may improve cancer outcomes by increasing survival time and reducing the incidence of new tumors. The antitumor effect of anticoagulants was first demonstrated in a study associating warfarin use with an improvement in median survival in patients with small cell lung cancer. ${ }^{35}$

A subgroup analysis of the all-cause mortality data in the CLOT trial showed that patients with solid tumors and no metastases who received LMWH had a $20 \%$ probability of death at 1 year compared with a $36 \%$ probability in patients receiving VKA. This translated to a $50 \%$ reduction in relative risk of death at 12 months with LMWH. ${ }^{36}$ This survival benefit did not correlate with an increased incidence of bleeding complications. However, no survival advantage with LMWH was noted in patients with metastatic disease. ${ }^{36}$

The randomized, placebo-controlled Fragmin Advanced Malignancy Outcome Study (FAMOUS) evaluated the effect of long-term dalteparin treatment on survival in patients with advanced malignancy. Although dalteparin did not significantly improve the overall 1-year survival rate, a survival benefit was seen in a subgroup analysis of patients with a good prognosis (i.e., those surviving $>17$ months after randomization; mean survival time was 43.5 months in the dalteparin group and 24.3 months in the placebo group). No significant increase in bleeding complications was seen in the dalteparin group compared with the placebo group. ${ }^{37}$
The Malignancy and Low Molecular Weight Heparin Therapy (MALT) trial also evaluated the effect of LMWH on survival rates. In this trial, patients with cancer but no known VTE were randomized to receive either nadroparin or placebo for 6 weeks. Treatment with LMWH was associated with a significant improvement in median survival time in the LMWH-treated patients compared with placebo recipients ( 8.0 vs. 6.6 months; $P=.021){ }^{38}$

A meta-analysis also showed improved survival in patients receiving LMWH. The pooled hazard ratio was $0.83(95 \% \mathrm{CI}, 0.74-0.99 ; P=.03)$ for all patients, and 0.86 (95\% CI, 0.74-0.99; $P=.04)$ in patients with advanced disease. The benefit of LMWH was consistent across the odds ratio, relative risk, and survival meta-analyses, and no significant increase in bleeding risk was seen (odds ratio, 1.51; 95\% CI, 0.25-9.20; $P=.65) .{ }^{39}$

A more recent study in patients with small cell lung cancer showed that overall tumor response rates rose from $42.5 \%$ in patients given chemotherapy alone to $69.2 \%$ in those who received chemotherapy plus dalteparin $(P=.07)$. Median overall survival increased from 8 to 13 months $(P=.01) .^{40}$ In contrast with other studies, improvement in survival time reported in this trial was similar in patients with localized cancer and in those with metastatic cancer. ${ }^{40}$ In a pilot study in small cell lung cancer, time to tumor progression was prolonged when enoxaparin was added to docetaxel chemotherapy. ${ }^{41}$

The most likely mechanisms by which LMWHs exert antineoplastic effects include inhibition of angiogenesis, inhibition of coagulation proteases such as thrombin and urokinase-type plasminogen activator, and apoptotic effects most likely mediated through alteration of DNA expression. ${ }^{42,43}$

\section{Current Recommendations for Extended Prophylaxis}

Although data support the efficacy and safety of secondary prophylaxis with LMWH in patients with cancer, the optimal duration and dosing regimens for long-term use have not been established. Insufficient data are available to determine the optimal duration of anticoagulation. Recently updated ACCP guidelines recommend at least 3 months treatment with LMWH (grade 1A) followed by LMWH or VKA as long as the cancer is active (grade $1 \mathrm{C}$; intermediate recommendation based on data from observational studies that may change when stronger evidence is available). ${ }^{9}$ 
The LMWHs enoxaparin, dalteparin, and tinzaparin are approved for the treatment of DVT in the United States. Dalteparin is indicated for the extended treatment of symptomatic VTE (proximal DVT and $\mathrm{PE}$ ) to reduce the recurrence of VTE in patients with cancer. ${ }^{44}$

\section{Advantages of LMWH Therapy}

LMWH therapy has a number of characteristics that translate into practical advantages: a favorable pharmacodynamic profile, resulting in a predictable and stable anticoagulant effect; rapid onset of action; high bioavailability; lack of drug and food interactions; and an elimination half-life of 3 to 6 hours. ${ }^{18} \mathrm{LMWH}$ can be given once daily as a subcutaneous injection, permitting outpatient treatment, and dose monitoring is not required (Table 2). These advantages may improve quality of life, reduce nursing time, and reduce recurrent VTE complications in high-risk cancer patients. Furthermore, as discussed in previous sections, LMWHs may also have direct anticancer effects that improve survival outcomes. ${ }^{43}$

\section{Economics of LMWH Treatment and Prophylaxis}

The average cost of treating a thromboembolic event is $50 \%$ higher in cancer patients than in the general patient population. The increased costs are due to both longer hospital stays and a higher incidence of bleeding complications. ${ }^{45,46} \mathrm{~A}$ recent economic analysis reported an average hospital stay of 11 days for patients with cancer and DVT at a cost of $\$ 1465$ per hospital day in 1997 U.S. dollars (\$1784 in 2002 dollars). ${ }^{45}$

Outpatient VTE prophylaxis using LMWH has the potential to reduce costs associated with anticoagulation monitoring and reduce hospital stays in patients without bleeding complications. A study of 100 patients with VTE, of whom $20 \%$ had cancer, reported that more than half of the patients with cancer could receive secondary prophylaxis with LMWH at home successfully. ${ }^{47}$ Therefore, although the acquisition costs of LMWH therapy are significantly higher than those of warfarin or acenocoumarol, these costs are offset by shorter hospital stays, reduced need for anticoagulant monitoring, and fewer bleeding complications.

A Canadian economic analysis was performed using data from the CLOT study to compare extended prophylaxis with daily subcutaneous injections of LMWH versus oral anticoagulation. ${ }^{48}$ This analysis

\begin{tabular}{|c|c|}
\hline Characteristic & Implication for Treatment \\
\hline $\begin{array}{l}\text { Predictable } \\
\text { pharmacodynamic } \\
\text { profile, good } \\
\text { bioavailability }\end{array}$ & $\begin{array}{l}\text { Reduced or eliminated need } \\
\text { or routine laboratory } \\
\text { coagulation monitoring; } \\
\text { outpatient therapy possible } \\
\text { in select patients }\end{array}$ \\
\hline $\begin{array}{l}\text { Quick onset and offset } \\
\text { of action (approximately } \\
12 \mathrm{~h} \text { ) }\end{array}$ & $\begin{array}{l}\text { Valuable when need to } \\
\text { interrupt treatment: invasive } \\
\text { procedure, bleeding episode, } \\
\text { chemotherapy-induced } \\
\text { thrombocytopenia }\end{array}$ \\
\hline $\begin{array}{l}\text { Subcutaneous } \\
\text { administration }\end{array}$ & $\begin{array}{l}\text { Eliminates concerns regarding } \\
\text { gastrointestinal absorption, } \\
\text { vomiting, diarrhea }\end{array}$ \\
\hline $\begin{array}{l}\text { Anticoagulant response } \\
\text { unaffected by dietary } \\
\text { factors or concomitant } \\
\text { drugs }\end{array}$ & $\begin{array}{l}\text { No interaction with } \\
\text { fluorouracil-based } \\
\text { chemotherapy }\end{array}$ \\
\hline $\begin{array}{l}\text { Outpatient treatment } \\
\text { possible }\end{array}$ & $\begin{array}{l}\text { Possible cost-savings from } \\
\text { reduced hospitalization; } \\
\text { potential quality of life } \\
\text { benefits }\end{array}$ \\
\hline Good safety profile & $\begin{array}{l}\text { Reduces clinical and } \\
\text { economic burden of bleeding } \\
\text { complications and adverse } \\
\text { events }\end{array}$ \\
\hline
\end{tabular}

concluded that although the LMWH regimen was associated with an additional cost (Canadian \$2159 per patient or $\$ 13,751$ per quality-adjusted life years [QALYs]), it was also associated with a gain of 0.157 QALYs. The authors concluded that LMWH is an economically acceptable option for preventing recurrent VTE in patients with cancer. ${ }^{48}$

\section{Patient and Physician Acceptance}

Patient Acceptance and Adherence: Because LMWHs have simplified dosing regimens and do not require routine anticoagulation monitoring in most patients, patient acceptance and adherence of VTE prophylaxis may be improved compared with warfarin therapy. A study of long-term LMWH prophylaxis in patients with terminal cancer found that LMWH was well accepted and regarded as an improvement in care. ${ }^{49}$ Another study found that patient adherence with anticoagulation therapy was $10 \%$ higher in the LMWH-treated patients compared with patients receiving warfarin..$^{48}$ 
Low Molecular Weight Heparins in Cancer

Outpatient Therapy: Outpatient LWMH therapy is feasible for many patients with cancer ${ }^{47,50}$ In addition to shortening hospital stays because of reduced need for monitoring, this approach may also minimize hospital visits. Patients can be taught to self-inject under the supervision of a hospital-based nurse, and oncedaily self-injection of LMWH has been shown to be as safe and effective as LMWH therapy administered by a home-care nurse. ${ }^{50}$ Assistance from home-care nurses or relatives may, however, be required for cancer patients who are incapable of self-injection, such as individuals who are elderly, have arthritis, or are sight-impaired.

Physician Acceptance: Despite ACCP guideline recommendations advocating the use of LMWH therapy as first-line treatment, a recent review of medical records for 100 consecutive patients treated for cancerrelated thrombosis at an anticoagulation clinic found that only 19 patients received long-term prophylaxis with LMWH (the remaining 81 received either LMWH or UFH for 5-7 days followed by warfarin for 3-6 months). Of these patients, 32\% did not receive long-term LMWH because the referring physician ordered long-term warfarin therapy ${ }^{51}$ For almost half the patients, long-term (3-6 months) LMWH was not used because the patient's medical insurance did not cover the cost and could not afford the out-of-pocket cost. Wittkowsky ${ }^{51}$ emphasized the need for educational efforts to health insurance providers and greater exposure to evidence-based guidelines to improve the acceptance and implementation of long-term LMWH for cancer-associated thrombosis.

\section{Future Considerations and Issues}

Many options are available for the future management of VTE in patients with cancer. LMWHs will continue to be important not only in preventing VTE but also in slowing rates of disease progression; several studies have shown that long-term cancer treatments, including LMWHs, prolong survival. However, this association, particularly the effects of differing drug regimens, cancer types, and their respective stages, requires further investigation.

Other agents are also under investigation for the treatment of VTE in patients with cancer, including fondaparinux, rivaroxaban, and dabigatran. Fondaparinux, by binding antithrombin, directly inhibits factor $\mathrm{Xa}$, thus reducing the production of thrombin. In early trials, fondaparinux has been shown to be as effective as, or more effective than, LMWHs in preventing DVT. More studies are needed to delineate whether fondaparinux has the same survival benefit in cancer as LMWHs.

Rivaroxaban is another factor Xa-inhibitor currently under investigation. Phase II results suggest that, when used for 5 to 9 days in patients with elective total hip replacement, rivaroxaban showed a reduction in the combined endpoint of any DVT, non-fatal PE, and all-cause mortality (15\% with dose of $2.5 \mathrm{mg}$ twice daily vs. $17 \%$ with enoxparin $40 \mathrm{mg}$ once daily), with a dose-dependent increase in the incidence of major postoperative bleeding. ${ }^{52}$ Apixaban is another factor Xa-inhibitor currently under phase II development. . $^{33}$

The direct thrombin inhibitor dabigatran has reported a dose-dependent decrease in VTE and bleeding complications in patients undergoing total knee or hip replacement. ${ }^{54}$ However, the efficacy and safety profiles of rivaroxaban, apixaban, and dabigatran for the long-term, secondary prophylaxis of VTE have not yet been reported. Currently, 2 studies investigating the use of dabigatran for acute treatment and secondary prevention of VTE are ongoing and are expected to be finalized by the end of 2009 .

Integral to the development of more effective anticoagulation for cancer patients is the need for further study into mechanisms of hypercoagulability with malignancy. Clearly, hemostatic pathways are linked to tumor progression and worse prognosis. A better understanding of the molecular pathways that facilitate neoplastic progression should improve our ability to treat both malignancy and associated VTE.

\section{Conclusions}

The risk of thrombosis in cancer patients is high even with the use of prophylactic anticoagulant therapy. Moreover, patients with cancer also have an increased risk of recurrent VTE despite prolonged prophylaxis, and may require a higher intensity of anticoagulation to prevent recurrence. Patients with cancer and VTE can benefit from effective extended thromboprophylaxis but are also at significant risk of bleeding during antithrombotic therapy. This issue is compounded by the problematic management of oral anticoagulants, such as warfarin, which until recently have been the mainstay of long-term prophylaxis in this patient group. 
The recently updated ACCP guidelines recommend at least 3 months treatment with LMWH followed by LMWH or VKA as long as the cancer is active. ${ }^{9}$ Studies suggest that for extended treatment and prevention of recurrence of VTE, LMWHs are associated with fewer thrombotic events and have at least a similar safety profile when compared with VKAs. Furthermore, LMWH has a more predictable anticoagulation profile, which is particularly important for cancer patients, who can have variable hemodynamics. The more predictable profile with LMWH leads to a reduced need for monitoring, and thus indirectly reduces the costs associated with treatment. Conversely, although LMWHs can be administered in an outpatient setting, they require subcutaneous injections, and VKAs are administered orally.

Additional research is needed to clarify the optimal intensity and duration of therapy for the different LMWHs and to further investigate their potential antitumor benefits. Further research is also needed to determine whether novel anticoagulants, such as direct factor $\mathrm{Xa}$ or thombin inhibitors, have a role not only in VTE prophylaxis and treatment, but also in the treatment of the cancers themselves. In the meantime, educational efforts are required to improve the acceptance and implementation of long-term LMWH therapy for cancer-associated VTE.

\section{References}

1. Heit JA, Silverstein MD, Mohr DN, et al. Risk factors for deep vein thrombosis and pulmonary embolism: a population-based casecontrol study. Arch Intern Med 2000;160:809-815.

2. Donati MB. Cancer and thrombosis. Haemostasis 1994;24:128-131.

3. Levitan N, Dowlati A, Remick SC, et al. Rates of initial and recurrent thromboembolic disease among patients with malignancy versus those without malignancy. Risk analysis using Medicare claims data. Medicine (Baltimore) 1999;78:285-291.

4. Khorana AA, Francis CW, Culakova E, et al. Thromboembolism is a leading cause of death in cancer patients receiving outpatient chemotherapy. J Thromb Haemost 2007;5:632-634.

5. Shen VS, Pollak EW. Fatal pulmonary embolism in cancer patients: is heparin prophylaxis justified? South Med J 1980;73:841-843.

6. Lee AY, Levine MN. Venous thromboembolism and cancer: risks and outcomes. Circulation 2003;107(23 suppl 1):I17-I21.

7. Caruso V, Iacoviello L, Di Castelnuovo A, et al. Venous thrombotic complications in adults undergoing induction treatment for acute lymphoblastic leukemia: results from a meta-analysis. J Thromb Haemost 2007;5:621-623.

8. Geerts WH, Bergqvist D, Pineo GF, et al. Prevention of venous thromboembolism: american college of chest physicians evidence-based clinical practice guidelines, 8th edition. Chest 2008;133:381S -453S.

9. Kearon C, Kahn SR, Agnelli G, et al. Antithrombotic therapy for venous thromboembolic disease: american college of chest physicians evidence-based clinical practice guidelines, 8th edition. Chest 2008;133:454S-545S.

10. Monreal M, Falgá C, Valdés M, et al. Fatal pulmonary embolism and fatal bleeding in cancer patients with venous thromboembolism: findings from the RIETE registry. J Thromb Haemost 2006;4: 1950-1956.

11. Hutten BA, Prins $M H$, Gent $M$, et al. Incidence of recurrent thromboembolic and bleeding complications among patients with venous thromboembolism in relation to both malignancy and achieved international normalized ratio: a retrospective analysis. J Clin Oncol 2000;18:3078-3083.

12. Palareti G, Legnani $C$, Lee $A$, et al. A comparison of the safety and efficacy of oral anticoagulation for the treatment of venous thromboembolic disease in patients with or without malignancy. Thromb Haemost 2000;84:805-810.

13. Prandoni $\mathrm{P}$, Lensing AW, Piccioli A, et al. Recurrent venous thromboembolism and bleeding complications during anticoagulant treatment in patients with cancer and venous thrombosis. Blood 2002;100:3484-3488.

14. Prandoni $\mathrm{P}$, Lensing AW, Cogo $\mathrm{A}$, et al. The long-term clinical course of acute deep venous thrombosis. Ann Intern Med 1996;125:1-7.

15. Palareti $G$, Cosmi B. Predicting the risk of recurrence of venous thromboembolism. Curr Opin Hematol 2004;11:192-197.

16. Heit JA, Mohr DN, Silverstein MD, et al. Predictors of recurrence after deep vein thrombosis and pulmonary embolism: a populationbased cohort study. Arch Intern Med 2000;160:761-768.

17. Ansell J, Hirsh J, Hylek E, et al. Pharmacology and management of the vitamin $\mathrm{K}$ antagonists: american college of chest physicians evidence-based clinical practice guidelines, 8th edition. Chest 2008; 133:160S-198S.

18. Hirsh J, Bauer KA, Donati MB, et al. Parenteral anticoagulants: american college of chest physicians evidence-based clinical practice guidelines, 8th edition. Chest 2008;133:141S-159S.

19. Masci G, Magagnoli M, Zucali PA, et al. Minidose warfarin prophylaxis for catheter-associated thrombosis in cancer patients: can it be safely associated with fluorouracil-based chemotherapy? J Clin Oncol 2003;21:736-739.

20. Deitcher SR. Dalteparin reduced recurrent venous thromboembolism more than oral anticoagulation in patients with cancer. ACP J Club 2004;140:10.

21. Lee $A Y$, Levine $M N$, Baker RI, et al. Low-molecular-weight heparin versus a coumarin for the prevention of recurrent venous thromboembolism in patients with cancer. N Engl J Med 2003;349:146153.

22. Bona RD, Sivjee KY, Hickey AD, et al. The efficacy and safety of oral anticoagulation in patients with cancer. Thromb Haemost 1995; 74: 1055-1058.

23. Schulman S, Beyth RJ, Kearon C, Levine MN. Hemorrhagic complications of anticoagulant and thrombolytic treatment: american college of chest physicians evidence-based clinical practice guidelines, 8th edition. Chest 2008;133:257S-298S.

24. Meyer G, Marjanovic Z, Valcke J, et al. Comparison of low-molecularweight heparin and warfarin for the secondary prevention of venous thromboembolism in patients with cancer: a randomized controlled study. Arch Intern Med 2002;162:1729-1735.

25. Zacharski LR, Prandoni P, Monreal M. Warfarin versus low-molecularweight heparin therapy in cancer patients. Oncologist 2005;10: $72-79$.

26. Hull R, Pineo G, Mah AF, et al. Long-term low molecular weight heparin treatment versus usual care in proximal-deep vein thrombosis patients with cancer. Am J Med 2006;119:1062-1072. 
Low Molecular Weight Heparins in Cancer

27. Deitcher SR, Kessler CM, Merli G, et al. Secondary prevention of venous thromboembolic events in patients with active cancer: enoxaparin alone versus initial enoxaparin followed by warfarin for a 180-day period. Clin Appl Thromb Hemost 2006;12:389-396.

28. Iorio A, Guercini F, Pini M. Low-molecular-weight heparin for the long-term treatment of symptomatic venous thromboembolism: metaanalysis of the randomized comparisons with oral anticoagulants. J Thromb Haemost 2003;1:1906-1913.

29. Ferretti G, Bria E, Giannarelli D, et al. Is recurrent venous thromboembolism after therapy reduced by low-molecular-weight heparin compared with oral anticoagulants? Chest 2006;130:1808-1816.

30. HullR, Pineo GF, Mah AF, et al. A randomized trial evaluating longterm low-molecular-weight heparin therapy for three months vs. intravenous heparin followed by warfarin sodium in patients with current cancer. J Throm Haemost 2003;(1 Suppl):P137a.

31. Hull R, Pineo G, Mah AF, et al. Long-term low molecular weight heparin treatment versus oral anticoagulant therapy for proximal deep vein thrombosis. Blood 2002;96:148a.

32. Walsh-McMonagle D, Green D. Low-molecular-weight heparin in the management of Trousseau's syndrome. Cancer 1997;80:649-655.

33. Eikelboom JW, Baker RI. Low-molecular-weight heparin for the treatment of venous thrombosis in patients with adenocarcinoma. Am J Hematol 1998;59:260-261.

34. Luk C, Wells PS, Anderson D, et al. Extended outpatient therapy with low molecular weight heparin for the treatment of recurrent venous thromboembolism despite warfarin therapy. Am J Med 2001; 111:270-273.

35. Zacharski LR, Henderson WG, Rickles FR, et al. Effect of warfarin anticoagulation on survival in carcinoma of the lung, colon, head and neck, and prostate. Final report of VA Cooperative Study \#75. Cancer 1984;53:2046-2052.

36. Lee AY, Rickles FR, Julian JA, et al. Randomized comparison of low molecular weight heparin and coumarin derivatives on the survival of patients with cancer and venous thromboembolism. J Clin Oncol 2005;23:2123-2129.

37. Kakkar AK, Levine M, Kadziola Z, et al. Low molecular weight heparin, therapy with dalteparin, and survival in advanced cancer: the Fragmin Advanced Malignancy Outcomes Study (FAMOUS). J Clin Oncol 2004;22:1944-1948.

38. Klerk CP, Smorenburg SM, Otten HM, et al. The effect of low molecular weight heparin on survival in patients with advanced malignancy. J Clin Oncol 2005;23:2130-2135.

39. Lazo-Langner A, Goss GD, Spaans JN, et al. The effect of low molecular weight heparin on cancer survival. A systematic review and metaanalysis of randomized trials. J Thromb Haemost 2007;5:729-737.

40. Altinbas M, Coskun HS, Er O, et al. A randomized clinical trial of combination chemotherapy with and without low-molecular-weight heparin in small cell lung cancer. J Thromb Haemost 2004;2:12661271.
41. Robert F, Busby E, Marques MB, et al. Phase II study of docetaxel plus enoxaparin in chemotherapy-naive patients with metastatic non-small cell lung cancer: preliminary results. Lung Cancer 2003;42:237-245.

42. Cosgrove RH, Zacharski LR, Racine E, et al. Improved cancer mortality with low-molecular-weight heparin treatment: a review of the evidence. Semin Thromb Hemost 2002;28:79-87.

43. Burris HA III. Low-molecular-weight heparins in the treatment of cancer-associated thrombosis: a new standard of care? Semin Oncol 2006;33(2 Suppl 4): S3-S16.

44. Fragmin prescribing information. Available at: http://www. fragmin.com. Accessed November 23, 2007.

45. Elting LS, Escalante CP, Cooksley C, et al. Outcomes and cost of deep venous thrombosis among patients with cancer. Arch Intern Med 2004;164:1653-1661.

46. Avritscher EB, Cantor SB, Shih YC, et al. Cost-minimization analysis of low-molecular-weight heparin (dalteparin) compared to unfractionated heparin for inpatient treatment of cancer patients with deep venous thrombosis. Support Care Cancer 2004;12:531-536.

47. Ageno W, Steidl L, Marchesi C, et al. Selecting patients for home treatment of deep vein thrombosis: the problem of cancer. Haematologica 2002;87:286-291.

48. Dranitsaris G, Vincent M, Crowther M. Dalteparin versus warfarin for the prevention of recurrent venous thromboembolic vents in cancer patients: a pharmacoeconomic analysis. Pharmacoeconomics 2006;24:593-607.

49. Noble SI, Finlay IG. Is long-term low-molecular-weight heparin acceptable to palliative care patients in the treatment of cancer related venous thromboembolism? A qualitative study. Palliat Med 2005;19:197-201.

50. Wells PS, Kovacs MJ, Bormanis J, et al. Expanding eligibility for outpatient treatment of deep venous thrombosis and pulmonary embolism with low-molecular-weight heparin: a comparison of patient self-injection with homecare injection. Arch Intern Med 1998;158: 1809-1812.

51. Wittkowsky AK. Barriers to the long term use of low molecular weight heparins for the treatment of cancer-associated thrombosis. J Thromb Haemost 2006;4:2090-2091.

52. Erikkson BI, Borris L, Dahl OE, et al. Oral, direct factor Xa inhibition with BAY 59-7939 for the prevention of venous thromboembolism after total hip replacement. J Thromb Haemost 2006;4: 121-128.

53. Turpie AG. Oral, direct factor Xa inhibitors in development for the prevention and treatment of thromboembolic diseases. Arterioscler Thromb Vasc Biol 2007;27:1238-1247.

54. Eriksson BI, Dahl OE, Buller HR, et al. A new oral direct thrombin inhibitor, dabigatran etexilate, compared with enoxaparin for prevention of thromboembolic events following total hip or knee replacement: the BISTRO II randomized trial. J Thromb Haemost 2005;3:103-111. 